\title{
MAPEAMENTO GEOMORFOLÓGICO DA BACIA HIDROGRÁFICA DO RIO CÁGADO (MG)
}

\author{
Carolina Campos Eduardo ${ }^{(a)}$, Roberto Marques Neto ${ }^{(b)}$, Felipe Pacheco Silva ${ }^{(c)}$ \\ (a) Discente do Programa de Pós-Graduação em Geografia da Universidade Federal de Juiz de Fora. Email: \\ carolcampos13@gmail.com \\ (b) Prof. Adjunto do Departamento de Geociências e do Programa de Pós-Graduação em Geografia da Universidade \\ Federal de Juiz de Fora. Email:roberto.marques@ufjf.edu.br \\ (c) Discente do Programa de Pós-Graduação em Geografia da Universidade Federal do Rio de Janeiro. Email: \\ feliipe.p@hotmail.com
}

\section{EIXO: SISTEMAS GEOMORFOLÓGICOS: ESTRUTURA, DINÂMICAS E PROCESSOS}

\section{Resumo}

O presente trabalho trata do mapeamento geomorfológico da Bacia Hidrográfica do Rio Cágado, no contexto da Zona da Mata Mineira, com procedimentos metodológicos amparados na hierarquia taxonômica do relevo, cujo reconhecimento dos modelados de dissecação e agradação foram representados, segundo as técnicas da cartografia geomorfológica do Manual Técnico de Geomorfologia. Desse modo, o mapa produzido na escala de 1/50.000 procura reconhecer o nível taxonômico dos padrões de formas semelhantes. Para esse fim, foram caracterizadas as unidades geomorfológicas classificando em modelados, realização dos cálculos morfométricos utilizando o grau de entalhamento da profundidade de dissecação e a dimensão interfluvial, bem como a nomenclatura para os conjuntos de sistemas de relevo correlacionada a carta de declividade, permitindo assim, mapear os compartimentos vinculados a uma dissecação estrutural, homogênea e agradacional contribuindo concomitante para interpretação da dinâmica da bacia claramente correlacionada a regimes de esforções neotectônicos, estes representados em grande medida pelos fatos geomorfológicos simbolizados.

Palavras chaves: cartografia geomorfológica, compartimentação morfológica, morfometria.

\section{Introdução}

Uma série de pautas metodológicas permeia a cartografia geomorfológica no Brasil e no mundo, campo que ainda padece de uma falta de consenso no concernente a um padrão de mapeamento do relevo em diferentes escalas. Como suporte ao mapeamento geomorfológico, Huggett (2007) sugere a identificação básica da paisagem através de fotografias aéreas ou mapas temáticos. Goudie (1981) recomenda o uso das fotografias aéreas para uma formulação prévia das principais formas de relevo, identificadas pelas tonalidades de cores monocromáticas ou cores verdadeiras.

Nesse sentido, diversas técnicas se oferecem para a concepção e análise geomorfológica destacando-se os estudos referentes ao conteúdo cartográfico do relevo. A cartografia conforme, Goulart (2001, p.25), consiste em linguagem eficiente "[...] para mediar a comunicação dos fatos do relevo e os sujeitos a quem a mensagem se destina". Ainda em referência ao mapeamento geomorfológico, Goudie (1981) destaca a 
variabilidade das técnicas dispensadas, colocando que as informações de medição, de escala e o tipo de informação são dados amplamente utilizados no mapa. O leque de possibilidades de interpretação geomorfológica é ampliado na medida em que se considera, além dos dados morfológicos, o conjunto das análises morfométricas, bem como os dados sobre os materiais e processos correlatos a gênese de formação de uma paisagem (GOUDIE, 1981).

A análise sistemática do mapeamento geomorfológico assegura a avaliação da paisagem quanto a informações referentes à sua gênese, cronologia, litologia, estrutura e aspectos morfográficos, conforme asseveram autores como Klimazewski (1963) e Tricart (1965). Sobre essas informações, Torres et al. (2012) esclarecem que para a produção do mapa geomorfológico demanda o levantamento de atributos estruturais, como a base geológica, dados morfográficos expressos pelas formas do relevo, informações morfométricas determinando o grau de declividade, amplitude altimétrica e dimensão interfluvial, a morfodinâmica representando os processos de superfície, e a cronologia, referenciando a idade pelo menos relativa do relevo.

Fushimi e Nunes (2008) destacam as metodologias de trabalho no campo voltadas para a elaboração de documentos cartográficos, discutindo como a prática de campo pode se voltar para o levantamento das informações que devem constar em um mapa geomorfológico.

A cartografia geomorfológica tem se apoiado no desenvolvimento das técnicas computacionais e de geoprocessamento, que vem provendo uma maior agilidade nas análises de informações geográficas e automação de expedientes correlacionados ao mapeamento mediante a aplicação de técnicas pautadas no Sistema de Informação Geográfica (SIG) (ROCHA, 2000). De encontro ao uso da informática no campo da Geomorfologia, para Souza e Sampaio (2010) a revolução e popularização do uso de microcomputadores contribuíram para os estudos das formas terrestres, através de imagens de satélites e das técnicas computacionais voltadas ao trato de tais produtos.

Com base no preâmbulo supraexposto, o presente paper empenhou-se em produzir o mapeamento geomorfológico da bacia hidrográfica do rio Cágado, localizada em área de relevo montanhoso emoldurado em altas cristas quartzíticas, que interceptam a porção meridional da Zona da Mata Mineira. Discute aspectos metodológicos da cartografia geomorfológica aplicada ao mapeamento de sistemas geomorfológicos montanhosos e o papel do mapa geomorfológico na interpretação dos aspectos genéticos, evolutivos e dinâmicos fundamentais do sistema geomorfológico em apreço. 
XVII Simpósio Brasileiro de Geografia Fisica Aplicada

I Congresso Nacional de Geografia Física
OS DESAFIOS DA GEOGRAFIA FÍSICA NA FRONTEIRA DO CONHECIMENTO

Instituto de Geociências - Unicamp

Campinas - SP

28 de Junho à 02 de Julho de 2017

\section{2. Área de Estudo}

A bacia hidrográfica do rio do Cágado, localizada na porção meridional da Zona da Mata Mineira, apresenta área de $1.131 \mathrm{~km}^{2}$ drenando na margem esquerda da Bacia do rio Preto, importante bacia do conjunto de bacias hidrográficas do rio Paraíba do Sul. A extensão do rio Cágado é de aproximadamente 144,7 km desde a nascente no município de Chácara até sua foz entre os municípios Santana do Deserto e Chiador. Ainda, abrange parcialmente os municípios de Bicas, Chácara, Chiador, Juiz de Fora, Mar de Espanha, Matias Barbosa, Santana do Deserto, Senador Cortes, e integralmente os municípios de Pequeri e Guarará, conforme a figura 1.

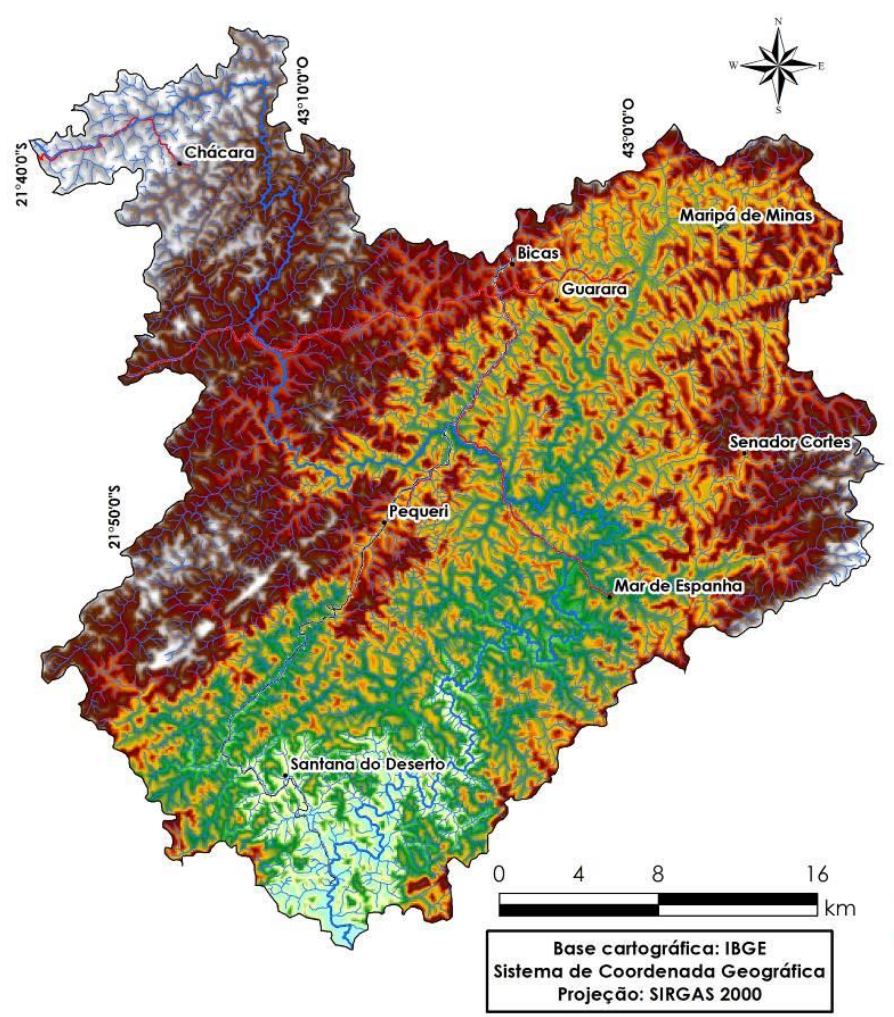

Figura 1 - Localização da Bacia Hidrográfica do rio Cágado.
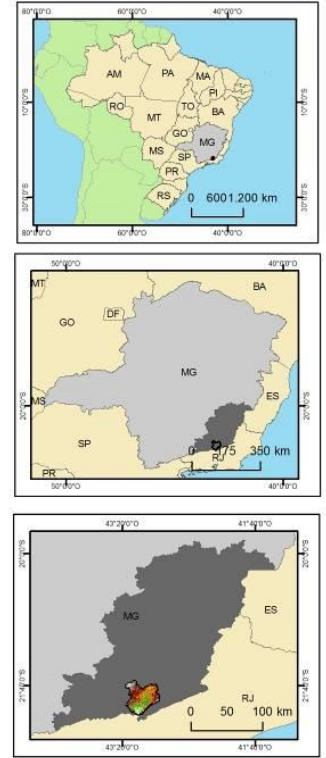

Convenções cartográficas:

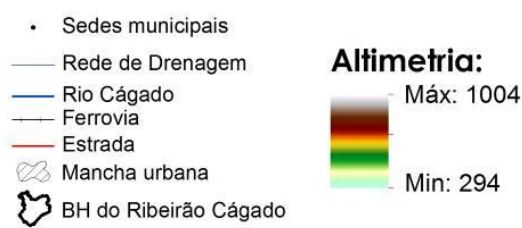

A bacia enquadra-se geomorfologicamente no contexto da Serra da Mantiqueira, no Domínio das Serranias da Zona da Mata Mineira. O relevo nesse domínio caracteriza-se pelas formas alongadas, marcado por escarpas adaptadas a falhas, sulcos estruturais, cristas simétricas alinhadas e linhas expressivas de cumeadas, conforme descrição de Gatto et al. (1983).

De acordo com os estudos realizados pela Companhia de Desenvolvimento Econômico de Minas Gerais CODEMIG (2013), a bacia está inserida no contexto das unidades geológicas formadas pelos Grupos Raposo, Complexo Quirino, Grupo Paraíba do Sul, Complexo Juiz de Fora e Suíte Matias Barbosa (Figura 


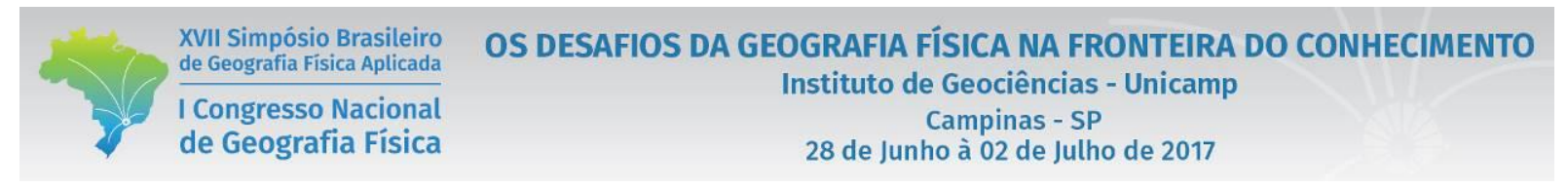

2), constituindo litologias de idade paleoproterozoica (2,5 - 1,6 Ga). O Grupo Raposo caracteriza-se por litofáceis de paragnaisses com participação subordinada de biotita, xisto, mármore, quartzito e anfibolitos. Já o Grupo Paraíba do Sul agrega litotipos em ortognaisses tonaliticos e granodioríticos. O Complexo Juiz de Fora abarca ortognaisses granuliticos e a Suíte Matias Barbosa incorpora litotipos de hornblendabiotita-gnaisses e leucognaisses.

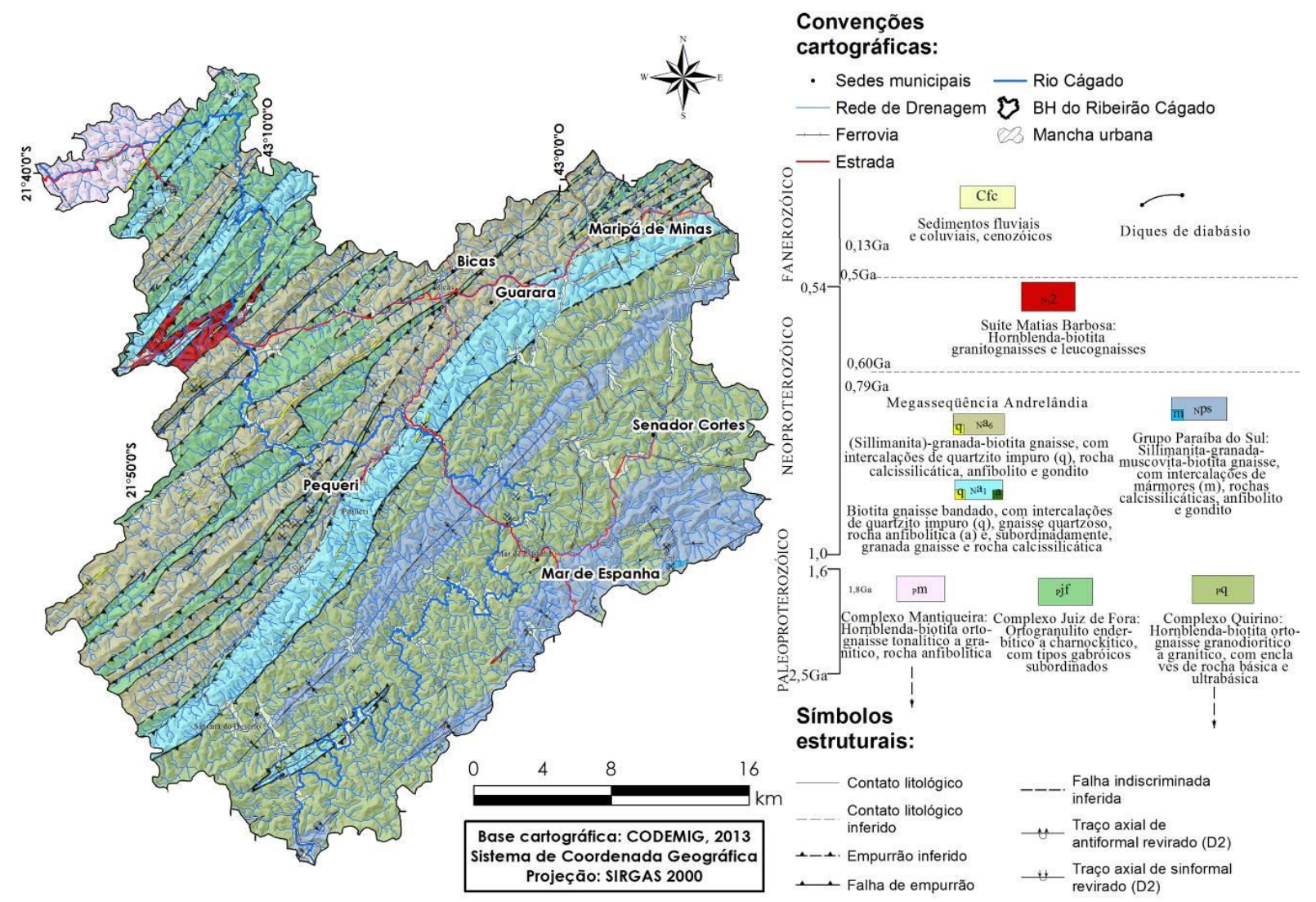

Figura 2 - Carta Geológica. Os autores.

Conforme o estudo de solos apresentados pelo Mapa de Solos do Estado de Minas Gerais (FEAM, 2010) a cobertura pedológica predominantemente na bacia é composta por LATOSSOLOS VERMELHO AMARELO. Nos compartimentos de dissecação em controle estrutural destacam-se os LATOSSOLO VERMELHO-AMARELO distrófico de textura argilosa e muito argilosa em relevo fortemente ondulado a montanhoso. Nas áreas urbanizadas de Mar de Espanha e Santana do Deserto, os solos do tipo ARGISSOLO VERMELHO AMARELO com textura argilosa a muito argilosa em relevo ondulado a forte ondulado se diferenciam das coberturas latolizadas encontradas majoritariamente nos demais núcleos urbanizados.

A bacia está sob a influência do clima tropical, do tipo $C w b$ pela classificação de Köppen, destacando maior concentração de chuvas no período de verão e escassez no período do inverno. A fitofisionomia 
original de Floresta Estacional Semidecidual sofreu processo de transformação associados aos ciclos econômicos cafeeiro, pecuário e pastoril, configurando em enclaves de florestas densas nas porções cuja declividade impediu avanço das ações antrópicas, arranjando-se uma paisagem composta por extensas áreas de pastagens e cultivo de Eucalyptus. Desse modo, os dados relacionados ao uso da terra extraídos por meio do processamento da imagem de satélite sensor TM/Landsat5 retratam o cenário predominante de pastagens nas feições de morros, enclaves de florestas nos compartimentos de dissecação estrutural e áreas antrópicas agrícolas como as pastagens e não agrícolas como as áreas dos núcleos urbanos.

\section{Materiais e Métodos}

Para a confecção do mapa geomorfológico da bacia do rio Cágado, a base de dados foi sistematizada lançando mão do Sistema de Informação Geográfica (SIG), através do software ArcGIS. Na extensão do Arc Catalog, criou-se um Geodatabase (.gbd), denominado "Mapa Geomorfológico", onde foram subdivididos os conjuntos de dados de feições pelas informações através do Dataset. Nesta subpasta foram geradas novas classes de feições pela função Features class, as quais se configuram em polígonos, pontos e linhas, de acordo com a necessária forma gráfica para representação do dado vetorizado.

Os planos de informações que congregaram o banco de dados referem-se às folhas topográficas (1/50.000) de Argirita (SF-23-X-D-V-1), Juiz de Fora (SF-23-X-D-IV-1), Mar de Espanha (SF-23-X-D-IV-4), Matias Barbosa (SF-23-X-D-IV-3), Sapucaia (SF-23-X-D-V-3), São João Nepomuceno (SF-23-X-D-IV-2) e Três Rios (SF-23-Q-II-2), disponibilizadas pelo Instituto Brasileiro de Geografia e Estatística (IBGE). As imagens de satélite TM/Landsat5, composição 453, são sugeridas por Nunes et al. (1994) como aquela capaz de permitir a verificação dos contatos entre os modelados e unidades geomorfológicas, a qual serviu para identificação da compartimentação geomorfológica.

O trato morfométrico seguiu a metodologia de Nunes et al. (1994), em que foi mensurada a dimensão interfluvial e a profundidade de dissecação nas folhas topográficas, e posteriormente vetorizadas no ArcGIS. A dimensão interfluvial corresponde à distância, em metros, entre linhas de drenagem ou pontos de surgência hídrica, e a profundidade de dissecação à amplitude, também em metros, entre os topos e os fundos de vale de referência, representando o quanto o canal foi capaz de entalhar (MARQUES NETO et al. 2015). Para cada valor medido apresenta-se um índice que varia de 1 a 5 , tanto para a dimensão interfluvial quanto para a profundidade de dissecação, cuja associação forma um conjunto composto por duas unidades numéricas, permitindo 25 correlações representativas da fragilidade. Desse modo, quanto maior o valor apresentado menor a dimensão interfluvial e maior é a profundidade de entalhe (CUNHA, 
2011). A leitura conjunta dos dois parâmetros morfométricos indica importantes aspectos de cunho morfodinâmico, permitindo deduzir elementos da energia intrínseca ao sistema geomorfológico em lume.

O SIG apoiou o trato morfométrico com a criação de pontos, cuja tabela de atributos incorporou informações sobre a intensidade de aprofundamento da drenagem e dimensão interfluvial, e em alguns pontos a indicação da referência local dada pela toponímia apresentada nas folhas topográficas quanto à nomenclatura das principais feições de relevo, como morros, serras, cachoeiras, dentre outros. O cálculo da dimensão interfluvial foi realizado com o recurso de "régua" da caixa de ferramentas do ArcGIS sobre as folhas topográficas digitalizadas, e posteriormente o dado numérico obtido foi digitado na tabela de atributos da feição de morfometria.

Congregaram o banco de dados informações de declividade, hipsometria e rede de drenagem. A carta de declividade também foi gerada no software ArcGIS (ESRI, 2015) tendo como base a imagem de radar SRTM (Shuttle Radar Topography Mission), pelo procedimento disponível na caixa de ArcToolBox $>$ Spacial Analyst Tools $>$ Surface $>$ Slope. Uma vez produzido, classificou-se o produto nas classes < 6\%; 6 - 15\%; 15 - 30\%; 30 - 45\%; 45-75\%; > 75\%, sugeridas por Silva et al. (2015).

$\mathrm{O}$ estabelecimento da nomenclatura dos modelados de dissecação se orientou pela proposta de Ponçano et al. (1981), a qual apresenta classes de informações clinográficas e de profundidade de dissecação, que associados resultam nos conjuntos de formas de relevo. Para isso, através do software adotado, ao plano de informação de declividade aplicou-se uma transparência de $75 \%$ para que de modo simultâneo fosse possível identificar o intervalo de declividade da feição do relevo e realizar o cálculo da amplitude altimétrica local.

As inserções de simbologias pontuais e lineares permitiram representar os elementos correspondentes à quinta ordem de grandeza, previamente identificados nas cartas topográficas e imagens de satélite e radar, assim como os alinhamentos de cristas, vales estruturais, capturas fluviais, desvios abruptos de drenagem; em decorrência da restrita dimensão espacial, as respectivas feições foram representadas por símbolos lineares e pontuais. Optou-se por preservar as curvas mestras com equidistância de 100 metros no intuito de se incorporar informações altimétricas. Com o propósito de se diferenciar no mapa as morfologias antropogênicas - definidas no presente estudo como àquelas geradas ou contundentemente transformadas pelo homem - se admitiu como estratégia a representação de tais setores através de hachuras sobrepostas aos modelados de dissecação e agradação. 


\section{Resultados e discussão}

Bakker (1963), ao abordar os diferentes tipos de mapeamentos geomorfológicos, debate quanto ao que o mapa geomorfológico deve conter e como são inseridas as informações no processo de mapeamento. Para o autor, o mapa geomorfológico deve possuir uma aplicação e ter um objetivo funcional. Como orientação à elaboração desse tipo de mapa, Bakker (1963) estabelece princípios de compromisso entre a caracterização morfográfica, a interpretação genética, os princípios de datação, a caracterização do substrato, a cobertura de sedimentação e pedológica para a confecção de um mapeamento geomorfológico. Moreira (1969) alerta quanto ao conteúdo das cartas geomorfológicas, que não figuram como meios descritivos dos fatos geomorfológicos, mas enfatizam a explicação e correlação entre os elementos. Enfaticamente, Ab'Sáber (1969) corrobora com esse principio ao alertar sobre a exaustiva simbologia geológica e morfológica de uma carta em elaboração, a qual, se não transmitir informações suficientes para a interpretação dos compartimentos e das formas de relevo associadas à paisagem morfológica, não consubstancia um documento geomorfológico (AB'SÁBER, 1969).

Quanto à confecção do mapa geomorfológico propriamente dito, a interpretação será mais eficiente e resoluta a partir da composição da legenda e dos estudos que repercutem no componente de legenda. Avançando no debate, Goudie (1981) coloca a legenda e o próprio mapa como ferramentas de análise geomorfológica. Ele orienta que as unidades geomorfológicas requerem simbologia que reflitam sua forma e extensão areal. Dessa forma, para as características estruturais e litológicas o autor recomenda a visualização por imagem sombreada, para a informação de gênese o uso de simbologia adequada, e a cronologia sendo representada pela graduação de cores, representando cada idade.

Com a aplicação das técnicas e amparados nos procedimentos metodológicos de Nunes et al. (1994) para a confecção do mapa geomorfológico reconhecem três tipos genéticos compostos pelos modelados de dissecação em controle estrutural (DE), modelados de dissecação homogênea (D) e modelados de agradação (A), conforme as figuras 3 e 4.

Os modelados de dissecação em controle estrutural associaram-se a declividades acima dos $30 \%$ e ao embasamento litológico mais resistente (ortogranulitos enderbiticos a charnockíticos do Complexo Juiz de Fora e litologias graníticas-gnáissicas do Grupo Paraíba do Sul e da Megassequência Andrelândia) (DUARTE et al., 2002). Os modelados de dissecação homogênea são marcados por declives médios entre $6 \%$ e $30 \%$ e morfologias mamelonares dissecadas pelo intenso retrabalhamento erosivo das coberturas superficiais argilosas que se desenvolvem sobre um substrato de litologias diversas compostos por rochas da Megassequência Andrelândia (biotita, gnaisse, plagioclásio, quartzo, k-feldspato, granada) e Complexo Quirino (biotitas, hornoblendas, gnaisses, quartzo, apatita, microclina) (DUARTE et al., 2002). No que 


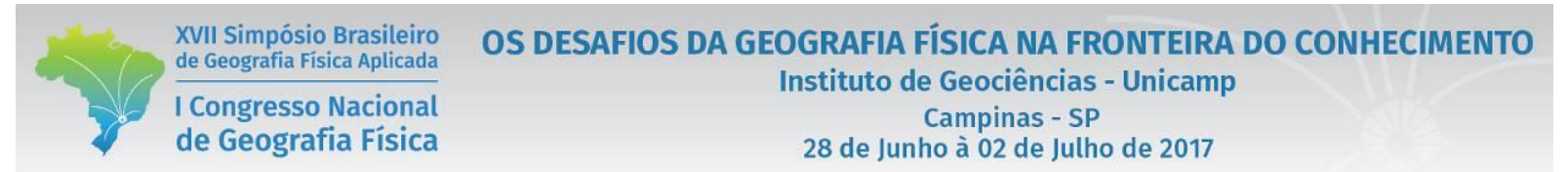

concerne aos modelados de agradação os mesmos congregam declives inferiores a $6 \%$, e são correlacionados a sedimentos fluviais e coluviais cenozóicos.

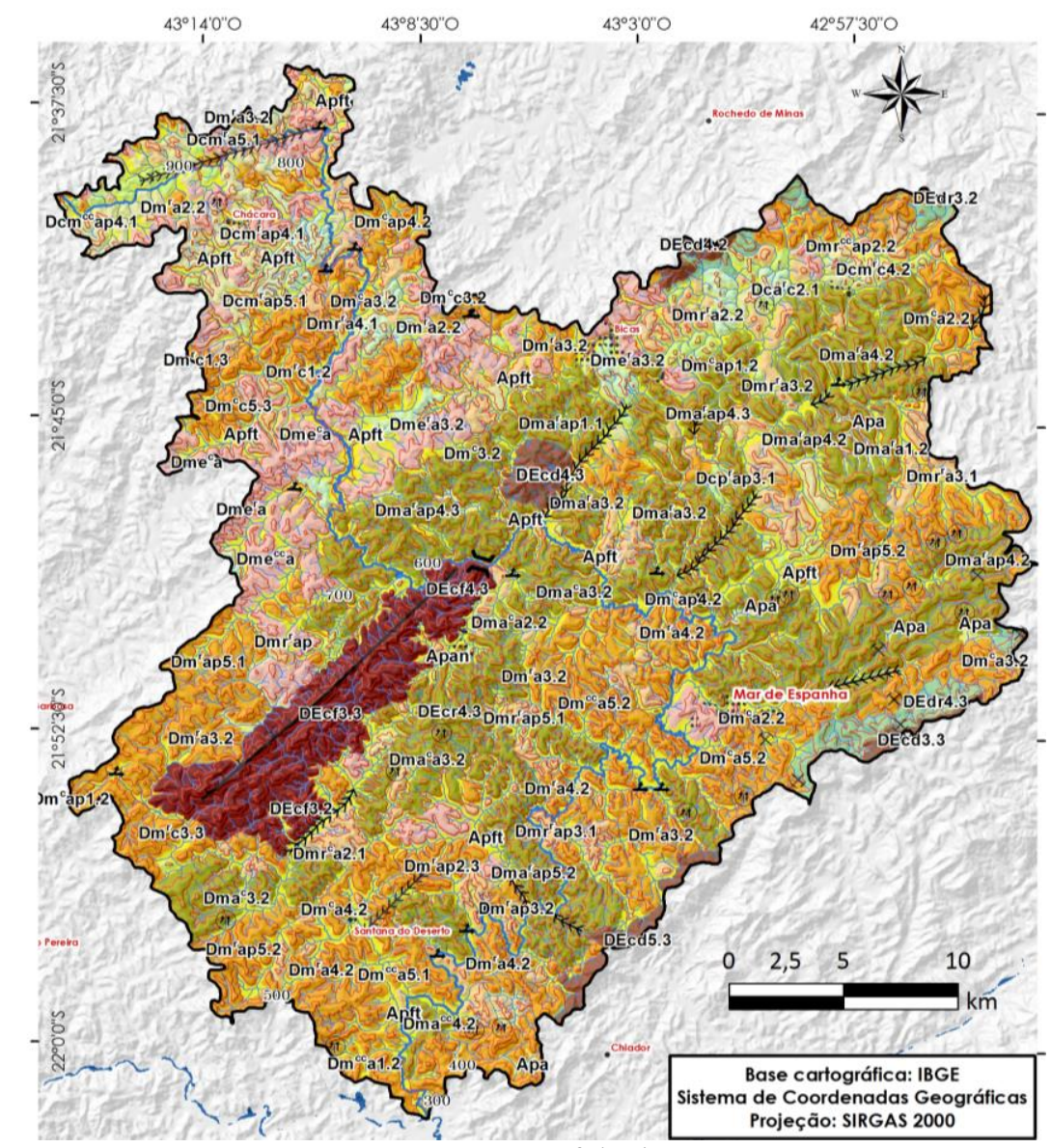

Figura 3 - Carta geomorfológica. Os autores.

Os modelados de dissecação em controle estrutural identificados para a bacia do Rio Cágado foram classificados em cristas festonadas (DEcf), cristas descontínuas (DEcd) e degraus reafeiçoados (DEdr). O compartimento de cristas festonadas é marcado por um nítido controle estrutural no sentido SW-NE, sendo caracterizando também por uma crista assimétrica estrutural que demarca os flancos escarpados da Serra da Piedade. Os compartimentos de cristas descontínuas caracterizam-se pelos arranjos disjuntos nos domínios da bacia de geoformas alongadas mais isoladas dispostas no sentido SW-NE. Predominantemente com topos aguçados e encostas retilíneas, o referido compartimento encontra-se associado aos degraus reafeiçoados, os quais se consubstanciam como zonas de transição dos modelados de dissecação estrutural para os modelados de dissecação homogênea, marcados por morfologias mamelonares. 


\section{Legenda:}

\begin{tabular}{|c|c|c|c|c|}
\hline MA & Apft & & & Apa \\
\hline M & \begin{tabular}{c|c|c|}
$\mathrm{s}$ & $\mathrm{Dcm}$
\end{tabular} & $\mathrm{Dmr}$ & $\mathrm{Dm}$ & \begin{tabular}{|l|l|} 
Dme & Dn
\end{tabular} \\
\hline DE & Dec & $\mathrm{Dec}$ & & Dedr \\
\hline
\end{tabular}

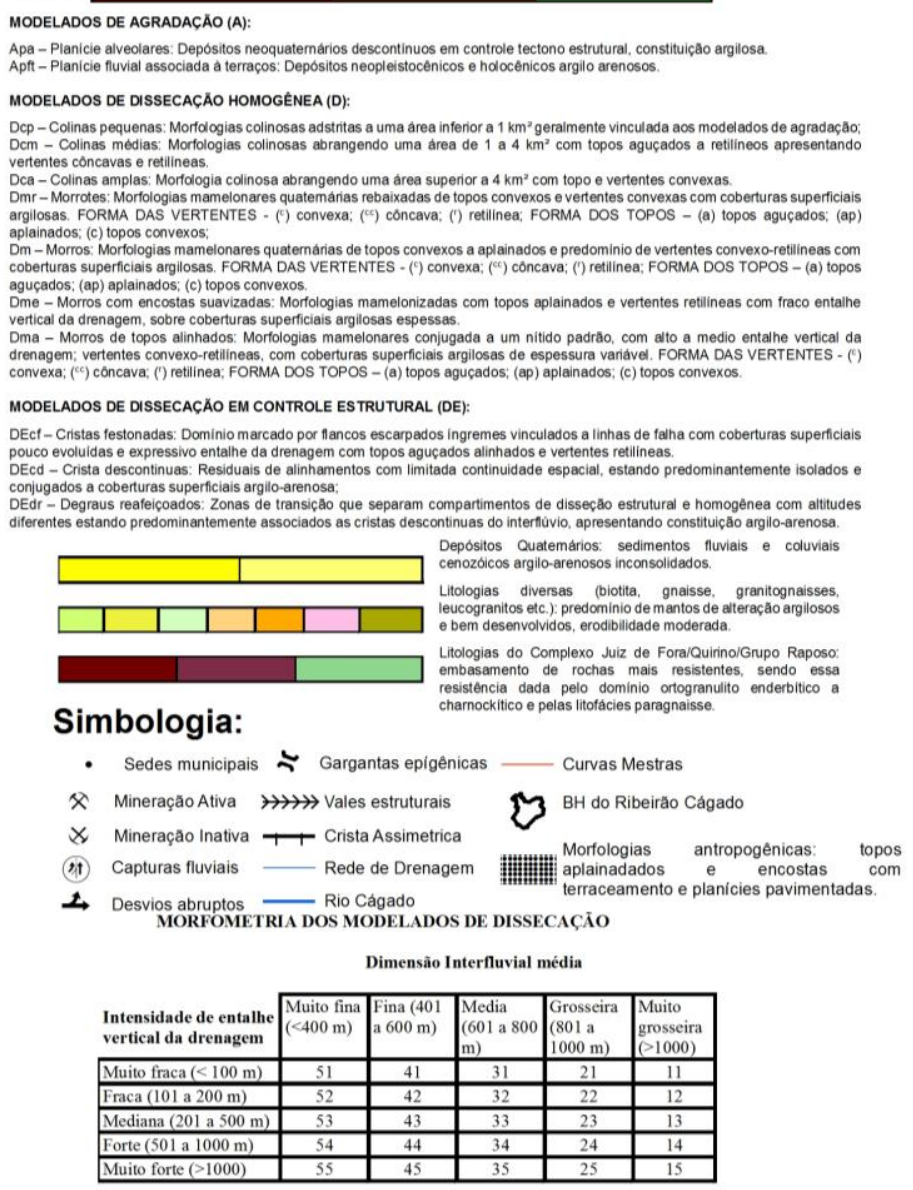

Figura 4 - Legenda do mapa geomorfológico.

Os modelados de dissecação homogênea são dados pelos compartimentos de colinas pequenas (Dcp), colinas médias (Dcm), colinas amplas (Dca), morrotes (Dmr), morros (Dm), morros com encostas suavizadas (Dme) e morros de topos alinhados (Dma). As colinas pequenas são morfologias com expressão areal inferior a $1 \mathrm{~km}^{2}$ geralmente associadas a modelados de agradação descontinuamente embutidos. As morfologias definidas como colinas médias, por sua vez, partilham de uma área entre 1 a 4 $\mathrm{km}^{2}$ adstritas a zonas transicionais de modelados de agradação e de dissecação estrutural. $\mathrm{O}$ compartimento de colinas amplas com área sempre superior a $4 \mathrm{~km}^{2}$ dá a tônica de expressiva porção do alto curso da bacia, congregando de modo mais contundente vertentes convexo-retilíneas e topos convexos. Os morrotes são marcados por morfologias mamelonares quaternárias em estágio avançando de rebaixamento, com topos e vertentes convexas. Prosseguindo, os morros se revelam como morfologias mamelonares predominantes na bacia, e apresentam vertentes convexo-retilíneas e topos convexos a 
aplainados relacionados a coberturas superficiais argilosas. Os morros com encostas suavizadas se projetam como compartimentos mamelonares com fraco entalhe da drenagem, apresentando topos aplainados e vertentes retilíneas, com perfis de intemperismo mais bem desenvolvidos, abrigando parcela significativa dos sítios urbanos dos municípios de Bicas e Mar de Espanha. O compartimento de morros de topos alinhados é marcado por um explícito padrão na disposição morfológica, o qual acompanha associações aos vales estruturais, e alinhados aos compartimentos em controle estrutural, como o morro do Monte Belo, próximo a Pequeri em conformidade a Serra da Piedade.

Os modelados vinculados a processos agradacionais foram discriminados em dois compartimentos: planícies fluviais associadas a terraços (Apft) e planícies alveolares (Apa). As planícies fluviais associadas a terraços podem ser definidas por depósitos neopleistocênicos (terraços) e holocênicos (planícies ativas), argilo-arenosos, e abrigam grande parte dos sítios urbanos da bacia. No geral, as áreas de estocagem sedimentar apresentam desenvolvimento lateral restrito quando relacionadas aos modelados de dissecação em controle estrutural, sendo mais desenvolvidas nas morfologias emolduradas em litologias mais tenras que definem os modelados de dissecação homogênea. As planícies alveolares também qualificadas por serem depósitos de formações recentes ou subatuais, possuem constituição argilosa. Estão vinculadas aos modelados em controle estrutural, como as cristas descontínuas na porção sudoeste da bacia, e aos modelados mamelonares de morros alinhados e morros com encostas suavizadas. A rede de drenagem caracteriza-se pelo aspecto retilíneo, conformando vales estruturais no sentido dominante SW-NE, acompanhando os compartimentos de dissecação em controle estrutural que também comportam cristas assimétricas claramente vinculadas à orientação imposta pela Zona de Cisalhamento do Rio Paraíba do Sul (ZCRPS), reconhecida por Dayan e Keller (1990) como uma deformação dúctil que promoveu a formação de rochas miloníticas com o bandamento bem marcado. Para a representação gráfica dessas incisões em forma de vale, bem como as escarpas apresentadas em cristas estruturais, seguiu-se a simbologia proposta pelo Manual Técnico de Geomorfologia (2009), e vetorizadas no software ArcGIS em formato de polilinhas para formas relacionadas à tectônica de falha.

$\mathrm{O}$ evidente controle tectônico que acomete as morfologias da bacia implicou em uma diversidade de fatos geomorfológicos, os quais apresentam reorganizações impressas pela ação neotectônica na bacia. As observações feitas nas cartas topográficas que contemplam a bacia em estudo, permitiram o reconhecimento dos fenômenos de feições anômalas da drenagem, como os desvios abruptos e capturas fluviais, sendo a representação cartográfica feita por pontos gráficos em software ArcGIS. Os desvios abruptos identificados na bacia foram considerados fatos geomorfológicos intimamente vinculados a um minguamento das planícies fluviais, enquanto as capturas fluviais majoritariamente foram associadas a 
faixas de transição de morfologias mamelonares, denotando nessas porções de relativa homogeneidade um controle tectônico mais bem registrado.

\section{Considerações finais}

A perseguição permanente dos desafios impostos pela cartografia geomorfológica foi em parte cumprida ao longo das fases de elaboração do presente trabalho, com alguns atributos representados de forma mais franca e explícita em detrimento de outros, cujas dificuldades metodológicas permitem uma representação de caráter mais acessório. Dessa maneira, os aspectos morfológicos e morfométricos foram os mais abrangentemente representados, cobrindo toda a bacia hidrográfica com famílias de cores específicas para os diferentes tipos genéticos, pontuadas pelos símbolos alfanuméricos atrelados à matriz de dissecação apresentada na legenda. A conjugação dos índices de dissecação, ainda, admite considerações de cunho morfodinâmico, uma vez que tais índices se relacionam diretamente à energia do relevo e permitem, por conseguinte, deduções plausíveis nesse sentido. Alguns aspectos morfoestruturais foram representados na forma de símbolos, sendo que os litotipos não partilharam do conteúdo do mapa pela inviabilidade em se sobrepor mais um layer na forma de hachura, recurso este utilizado para a diferenciação das morfologias antropogênicas. Por fim, o atributo de representação mais dificultosa foi a morfocronologia, cuja incorporação esteve restrita às considerações gerais e relativas contidas no corpo da legenda. A dificuldade de levar a efeito a datação absoluta do relevo, sobretudo das morfologias denudacionais, impõe restrições na representação dos aspectos cronológicos nos mapas geomorfológicos.

Malgrado a falta de uniformidade de representação do relevo e às dificuldades intrínsecas, a abordagem metodológica aqui apresentada tem por mérito admitir a incorporação relativamente balanceada dos diferentes parâmetros que o mapa geomorfológico deve conter. O produto cartográfico final, por seu turno, subsidia contundentemente a interpretação do sistema geomorfológico local, bastante representativo do domínio tropical atlântico e suas tipicidades geomorfológicas que intercalam morfologias convexas com mantos de alteração profundos e modelados em controle estrutural, sinalizando o potencial de aplicação da metodologia trabalhada tanto em sistemas geomorfológicos similares como em contextos distintos.

\section{Bibliografia}

AB'SÁBER., A.N. Problemas do Mapeamento Geomorfológico no Brasil. Geomorfologia. n.06, IG-USP,São Paulo, 1969. 
BAKKER, J.P. Different Types of Geomorphological Maps. In: KLIMASZEWSKI,M. The Principles of The Geomorphological mapping in Poland. Geographical Studies. Problems of Geomorphological Mapping, v.46,1963.

COMPANHIA DE DESENVOLVIMENTO ECONÔMICO DE MINAS GERAIS (CODEMIG). Mapa Geológico Folha S F.23-X -D-IV- JUIZ DE FORA. Belo Horizonte, 2013. Escala 1:100.000.

CUNHA, C. M. L. A. A cartografia a geomorfológica em áreas litorâneas. Tese (Livre Docência em Geografia): Rio Claro, UNESP, 2011.

DAYAN, H.; KELLER, J. V. A. A Zona de Cisalhamento do Rio Paraíba do Sul nas vizinhanças de Três Rios (RJ): uma análise da deformação dada por algumas feições estruturais. Revista Brasileira de Geociências, v. 19, n. 4, p. 494-506, 1990.

DUARTE, B. P. HEILBRON, M., NOGUEIRA, J. R., TUPINAMBÁ, M., EIRADO, L. G., VALLADARES, C. S., ALMEIDA,J. C. H., ALMEIDA,C. G. Geologia das Folhas Juiz de Fora e Chiador. In: PEDROSA-SOARES, A.C. (Coords) Projeto Sul de Minas. Etapa I: Geologia e recursos minerais do sudeste Mineiro. Belo Horizonte: COMIG/UFMG/UFRJ/UERJ, cap. 6, 2003. CD-ROM.

FEAM. FUNDAÇÃO ESTADUAL DE MEIO AMBIENTE. Mapas de Solos do Estado de Minas Gerais. Banco de Solos de Minas Gerais, 2010.

FUSHIMI, M.; NUNES, J. O. R. Mapeamento Geomorfológico no Município de Presidente Prudente - SP, Brasil..IX Semana de Geografia. Unesp, Presidente Prudente,2008. Disponível em: <http://www4.fct.unesp.br/cursos/geografia/CDROM_IX SG/Anais\%20-\%20PDF/Melina\%20Fushimi.pdf〉. Acesso em: janeiro, 2017.

GATTO, L.C.S.; RAMOS, V.L.S.; NUNES, B. T. A.; MAMEDE, L.; GÓES, M. H. B.; MAURO, C. A.; ALVARENGA, S. M.; FRANCO, E. M. S.; QUIRICO, A. F.\&NEVES, L. B. Geomorfologia. In: Projeto RADAMBRASIL, Brasília: DNPM, v. 32, p. 305-384, 1983.

GOULART, A. C. O. Relevos e processos dinâmicos: uma proposta metodológica de cartografia geomorfológica. Geografares, Vitória, n.2, jun., p.25-40, 2001.

GOUDIE, A. Geomorphological techniques. London: George Allen \& Unwin, 1981. 395p.

HUGGETT, R. J. Fundamentals of Geomorphology. Routlege, London, 2007.

MARQUES NETO, R., ZAIDAN, R. T., MENOR JUNIOR, W. Mapeamento Geomorfológico do Município de Lima Duarte (MG). Revista Brasileira de Geomorfologia, v. 16, 123-136, 2015.

MOREIRA, A. A. N. Cartas Geomorfológicas. Geomorfologia. n.5, IG-USP, São Paulo, 1969.

NUNES, B. A.; JULIANTES, R. L.; CALDEIRON, S. S. Manual técnico de geomorfologia. Rio de Janeiro: IBGE, 1994. 111p

PONÇANO, W. L; CARNEIRO, C. D. R; BISTRICHI, C. A; ALMEIDA, F. F. M; PRANDINI, F. L. Mapa geomorfológico do estado de São Paulo. Vol. 1. Instituto de Pesquisas Tecnológicas, Divisão de Minas e Geologia Aplicada, 1981.94p

ROCHA, C. H. B. Geoprocessamento: Tecnologia Transdisciplinar, Editora: UFV, 2000.

ROSS, J. L. S., 1992. O registro cartográfico dos fatos geomórficos e a questão da taxonomia do relevo. Revista do Departamento de Geografia. FFLCH-USP. n. 6. São Paulo.

SILVA, F. P., MARTINS, C. A. H., MARQUES NETO, R., OLIVEIRA, E. L. N., FERNANDES, R. A. Mapeamento Geomorfológico da Bacia Hidrográfica do Ribeirão Santa Bárbara, Zona da Mata Mineira. Revista Brasileira de Geografia Física, v. 8, n. 3, p. 893-908, 2015.

SOUZA, L. F.; SAMPAIO, T. V. M. Aplicação do índice de Concentração da Rugosidade à identificação de classes de dissecação do relevo; uma proposta de quantificação e automatização em ambiente em SIG. In: III Simpósio Brasileiro de Ciências Geodésicas e Tecnologias da Geoinformação. Recife, 2010.

TORRES, F.T.P., MARQUES NETO, R.; MENEZES, S. B. Introdução à Geomorfologia. São Paulo: Cengage Learning, 2012. 


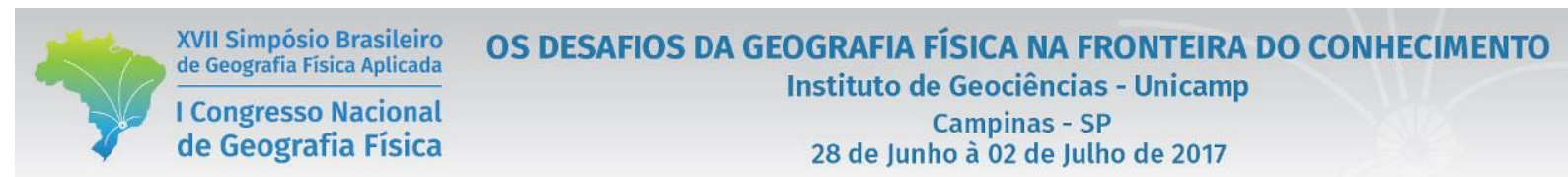

TRICART, J. Principés et méthods de la géomorphologie. Mason: Paris, 1965. 496p.

KLIMASZEWSKI, M. The Principles of the Geomorphological mapping in Poland. Geographical Studies. Problems of Geomorphological Mapping, v.46,1963. 